\title{
APPARENT OUTBREAK OF GASTROINTESTINAL DISEASE
}

A report in the Tamworth Newspaper the Northern Daily Leader, on May 16 alleged there was an outbreak of gastrointestinal disease at Farrer Agricultural High School, just outside Tamworth. The paper said 260 students had suffered symptoms including "gastric problems and constant vomiting" over the previous seven weeks (this period corresponded to the return from the Easter holiday). This was revised to 272 on May 17 in a follow-up report indicating the problem was continuing.

Farrer is a boys high school with a student intake locally and from a wide area of NSW. There are 468 students, about 300 of whom are boarders, and 90 staff. Students from year 7 to year 12 are enrolled (ie ages 12 to 18 ). As an agricultural school it has a farm section which includes dairy and beef cattle, pigs, chickens and one horse. A vegetable garden. tended by students provides some vegetables for consumption at the school.

\section{INVESTIGATION}

Senior staff at Farrer Agricultural High School expressed concern about an apparent excess of gastrointestinal illness at the school, so a decision was made to undertake a formal investigation. New England Region Public Health Unit (NER PHU) requested assistance from the Health Department's Epidemiology and Health Services Evaluation Branch with the epidemiologic aspects of the investigation.

Initial inquiries by NER PHU staff were directed at clarification of the media reports, which had implicated the school water supply. An assessment of school water was begun by the senior Environmental Health Officer in co-operation with Public Works Department staff.

Records of attendance at Farrer's sickbay were examined for the school year to date in an attempt to define recent illness patterns at the school. Class rolls indicated that a rise in school absences did occur during the fortnight from April 29 (Figure 1). We then examined the sickbay records for 1991 and determined that the increase in absences corresponded with a rise in sick-bay attendance. This change in the pattern of illness included elevations in the number of students presenting with upper respiratory tract and gastrointestinal symptoms (Figure 2). On this basis a preliminary case definition specified reporting of symptoms of diarrhoea, nausea, and/or vomiting and respiratory tract symptoms.

Having confirmed the impression of excess illness, and finding some evidence for recent change in the pattern of illness, we had to determine if the Farrer experience differed from local background rates of these illnesses. To obtain comparable information from a control group a similar examination of records was made at Calrossy Girls School where sickbay records and class rolls were examined for the current term (at Calrossy, beginning April 15). Calrossy Girls High School is in Tamworth and has a similar mixture of day and boarding students (156 and 200 respectively), of comparable age range to those at Farrer.

A questionnaire was designed to obtain information on rates of certain health problems (throat infection, diarrhoea, vomiting, nausea, headache and skin infections). Symptoms were defined on the basis of the subjective report of affected individuals.

A cohort study was thus carried out, with exposure defined as attendance at Farrer between April 10 (return from the Easter holiday) and May 17 (the end of the week in which the problem came to public attention). Controls were

\section{FIGURE 1}

FARRER SCHOOL OUTBREAK INVESTIGATION STUDENTS ABSENT FROM SCHOOL

STUDENTS ABSENT

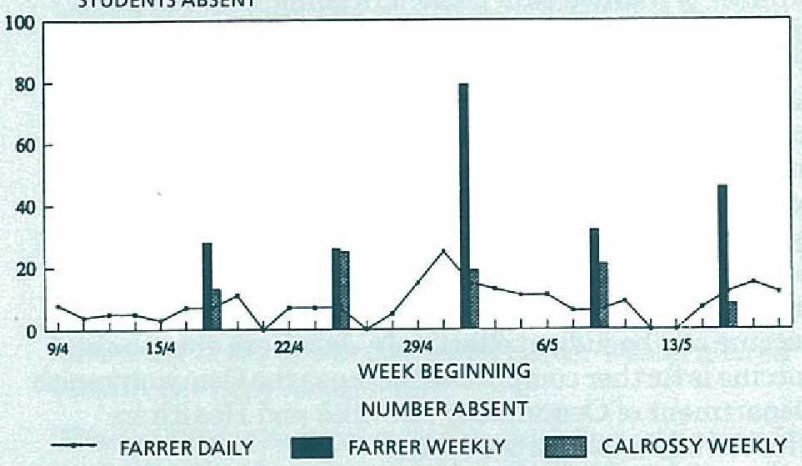
SOURCE: FARRER
CLASS ROLLS

\section{FIGURE 2}

FARRER SCHOOL OUTBREAK INVESTIGATION RESPIRATORY AND GASTROINTESTINAL ILLNESS

NUMBER OF STUDENTS AFFECTED

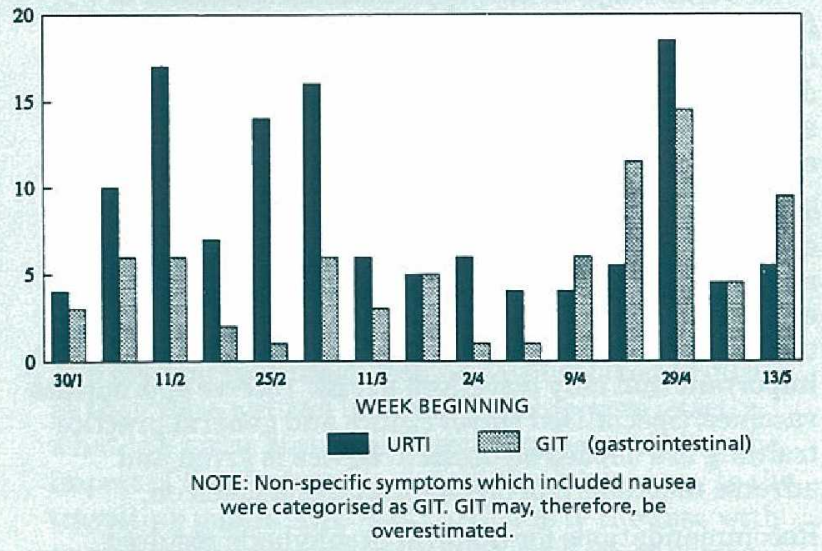

SOURCE: FARRER

defined as having attended Calrossy during the same period. Identical questionnaires were given to the control school students and staff on the same morning.

Variables examined included water (being a student or staff member at Farrer was taken as a proxy for exposure to Farrer's water supply), food prepared at Farrer, working in certain areas at Farrer (the vegetable garden, the dairy and work involving contact with cattle, pigs or chickens).

Investigations by the NER PHU Environmental Health Officer included sampling of water at Farrer to determine any contamination. Staff of the Department of Public Works were involved in this process. The Regional food inspector examined food preparation and processing and collected 13 specimens for microbiological examination. Stool samples were collected from students presenting at Farrer's sickbay with gastrointestinal symptoms.

\section{RESULTS}

A total of 923 questionnaires was completed -539 from Farrer and 384 from Calrossy. This represents a response 


\section{Gastrointestinal disease}

\section{- Continued from page 131}

rate of 97 per cent at Farrer and 88 per cent at Calrossy.

Results of sampling undertaken as part of the investigation were available during the following week. Rotavirus was isolated from one of the four stool samples collected from Farrer students attending the sickbay with gastrointestinal symptoms (diarrhoea with or without vomiting).

The Department of Public Works confirmed admixture of untreated water in the Farrer water supply. Four samples were collected from taps at Farrer on May 15. Two showed elevated levels of total coliforms but no faecal coliforms were isolated.

The Tamworth water supply is largely obtained from the Dungowan Dam. Farrer's water is supplied via a branch pipe. This water is chlorinated but has not passed through the townwater treatment works. Seventy-six other users receive water from this branch pipe proximally to Farrer and one distally. There were no NER PHU reports of similar illness from these sites. These investigations also revealed that some, at least, of the water available for drinking came directly (ie untreated) from the Peel River.

We entered data from the cohort study into an Epi-info 5.0 data base and used Epi-info for analysis, calculating frequencies of and relative risk for reported symptoms. The study demonstrated elevated rates of diarrhoea (RR 3.53, 95 per cent CI 2.37-5.28) and vomiting (RR 1.58, 95 per cent CI 1.02-2.45) associated with attendance at Farrer School. This involved boarder students especially but also day students and staff. Local community risk was determined by calculating relative risk for those recording the postcode of residence as 2340 (Tamworth). This was 0.53 (95 per cent CI $0.38,0.75$ ) for diarrhoeal symptoms.

We examined the potential relationship between consumption of food prepared at school and reports of illness. A significant trend towards reporting diarrhoea at Farrer with increasing consumption of meals prepared there (Chi-square for trend $-20.44, \mathrm{df}=6, \mathrm{p}<0.001$ ) was demonstrated. When we stratified according to day/boarder status, however, this trend was not significant (Chi-square for trend $=0.0043$, $\mathrm{df}=6, p=0.84$ ). Eating more meals at Farrer was associated with being a boarder rather than illness as such.

\section{Discussion}

We demonstrated an elevated risk of mild gastrointestinal symptoms among students and staff at Farrer High School (compared with Calrossy Girls School) during the period April 9 to May 17. The explanation for this excess was not clear from this study. Water sampling, though confirming admixture of treated and untreated (river) water at Farrer, did not implicate the water supply as a cause of illness.

The systematic investigation of an acute disease outbreak compromises: (i) preliminary inquiry; (ii) identification of cases; (iii) collection of data; (iv) analysis of data; (v) control; (vi) communication, and (vii) further epidemiological and laboratory investigations. The preliminary inquiry was able to confirm that a problem existed (ie, community concern) although the existence of the reported episode of disease was less certain. Confirming a diagnosis was difficult in the absence of local laboratory surveillance, samples from affected students and continuing acute presentations. No immediate control measures were felt necessary given the lack of evidence for a continuing problem, the mild nature of symptoms described and the uncertainty about a real excess of illness above local background rates.
Case identification involved reviewing sickbay and class records and contact with the local GPs. We developed a case definition on the basis of this information, and the initial media reports, which we took as a barometer of community concern. A clear case definition is an essential prerequisite to an epidemiological investigation. Initially it should be broad enough to allow for uncertainty but will ideally be narrowed with additional information. Our initial definition was maintained, in the absence of specific diagnostic information, as being appropriate to dealing with the problem as it existed.

A special study was needed to enable a more accurate description of the disease and determination of risk. We hypothesised that some excess risk existed at Farrer, perhaps due to exposure to untreated drinking water.

Data was therefore collected from those exposed to the water supply, to food prepared and any viral respiratory infections at Farrer and from a comparable group not exposed to these factors (Calrossy Girls High School). A major potential inadequacy of the study concerned measurement bias. This includes recall bias and the subjectivity of a report of 'diarrhoea' with no quantification of motions per day. We assumed that the bias in recalling symptoms over two months would be equal at the two schools, however, the publicity surrounding the Farrer 'outbreak' may have influenced recall at Farrer.

Data were analysed within the three classical epidemiological parameters of time, place and person. Time was problematic as the investigation was conducted six weeks after the initial cases were said to have occurred. Nevertheless an epidemic curve was drawn for both schools for the current term (from April 9), shown in Figure 1. Though not providing information to suggest, for example, a common agent or point source of infection, this curve indicated a change in illness during the period implicated by the media reports. The geographic distribution of cases was clear, though we attempted to define a more localised illness pattern within Farrer (eg by dormitory).

Analyses by 'person' included analysis by status (ie teacher, boarding or day student), food histories, exposure to specific areas at Farrer including the dairy and vegetable garden.

Specific control measures were not required, however advice about certain food-handling techniques and hygiene was provided. Removal of interconnections between river and treated water was essential regardless of the results of our investigation. Survelliance of control measures introduced is an essential part of control of a disease outbreak. NER PHU arranged for a prospective study of presentations to Farrer sickbay to answer the question (posed in media reports) of a continuing excess of illness at Farrer.

The NER PHU was confronted with reports of a cluster of gastrointestinal illness among students of a local school. A systematic approach, utilising the skills of a range of PHU and E\&HSEB staff, enabled a rapid assessment of risk and potential aetiology. A review of Farrer water supply, food handling and processing and sickbay arrangements was undertaken in conjunction with assessment of the acute disease outbreak. The PHU was thus able to reassure the local community and to recommend measures to Farrer School, aimed at improving their ability to deal with illness within the school and general hygiene precautions, within a short time of the initial reports.

Glenn Close and Michael Levy,

Epidemiology and Health Services Evaluation Branch

John Rooney,

New England Region Public Health Unit 